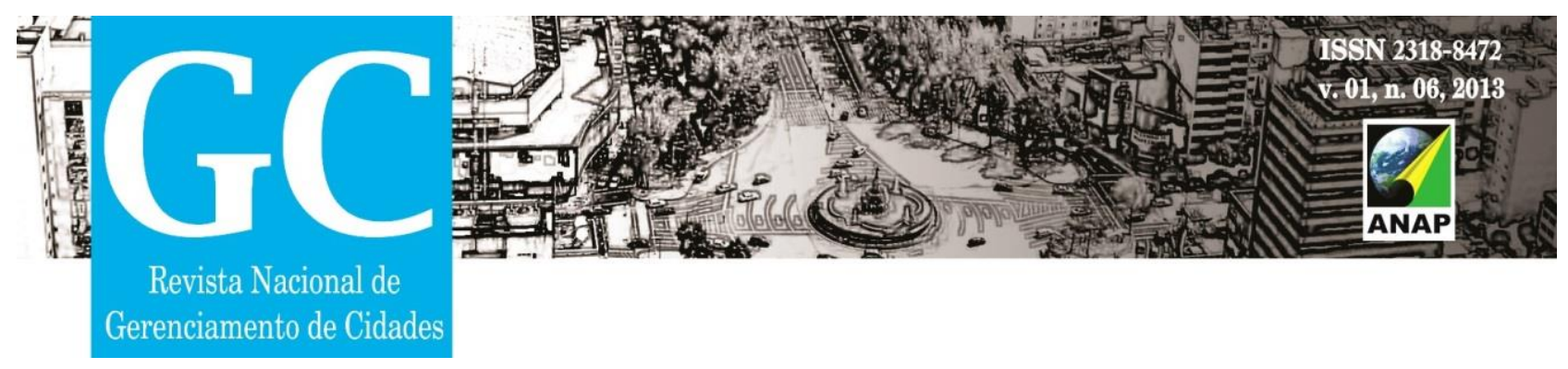

\title{
GESTÃO DA CONSTRUÇÃO CIVIL EM OBRAS DE TRANSPORTE: OBSERVAÇÕES A CERCA DE SUSTENTABILIDADE
}

\section{Bruno Borges Mamede ${ }^{1}$}

\section{Lucas Devides Moreno²}

Resumo: Este artigo visa responder ao questionamento acerca dos efeitos da má gestão de obras em Construção Civil, tanto para a cidade como para a sociedade, indicando alguns problemas e soluções observados na realização de obras voltadas para infraestrutura de Transportes. Grande parte destas é vital para o estabelecimento de relações diversas entre localidades e, também, determinam o uso e ocupação dos espaços de acordo com sua acessibilidade perante outras áreas da uma determinada zona urbana. Visto isto, a importância adequada do uso de seus materiais e pessoal não apenas cumpre a função de sustentabilidade, mas também salva recursos naturais e permite a maior durabilidade das estruturas em questão.

Palavras-Chave: Infraestrutura de Transportes. Engenharia Urbana. Sustentabilidade. Geografia Urbana.

\footnotetext{
${ }_{1}^{1}$ PEU/POLI/UFRJ / bruno.mamede@poli.ufrj.br

2 PEU/POLI/UFRJ / lucas.moreno@poli.ufrj.br
} 


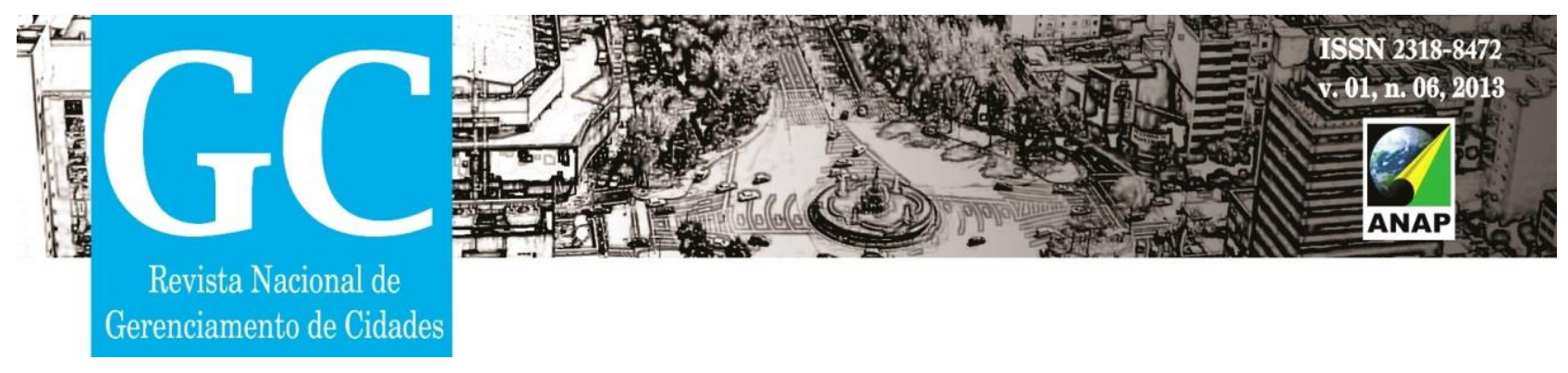

INTRODUÇÃO: PROPOSTA E OBJETIVO

Tal como apresentado, o objetivo deste artigo está em clarificar o debate a cerca da má gestão da construção civil brasileira na atualidade em face da utilização inadequada ou mesmo ineficiente dos recursos disponíveis. Como plano de fundo para tal discussão, busca-se utilizar a construção de infraestruturas de transportes, tanto de passageiros como de cargas, e sua devida correlação com o cotidiano urbano para esclarecer tal questionamento.

Desta maneira, não apenas serão vistos conceitos e abordagens presentes apenas na Engenharia Civil, mas sim em outros campos da mesma ciência, como as Engenharias Urbana, de Produção e de Transportes, além de outros presentes na Administração (Financeira, Logística e da Produção), Economia e Geografia. Mesmo que a pretensão seja muito ampla, o objetivo é demonstrar não apenas que a maneira como a gestão é capaz de determinar o produto final da construção, este insere-se em uma realidade onde a abordagem de análise é completamente multidisciplinar e demanda soluções que transpassam o alcance de apenas uma área do conhecimento científico.

A justificativa para este trabalho não está apenas na resposta ao questionamento sobre a gestão na construção de infraestruturas de transportes, mas sim como os seu impactos e resultados finais são capazes de provocar alterações significativas no cotidiano de uma determinada área urbana, independente da quantidade de localidades envolvidas. Doravante, a discussão também está incluída na questão sobre a sustentabilidade, tanto econômica como ambiental, nas obras de Engenharia Civil, a qual certamente é fomentada pelo uso intensivo de recursos das mais diversas naturezas.

A metodologia utilizada está pautada na revisão bibliográfica do tema nos campos de conhecimento já apresentados, buscando fomentar o debate sobre como a gestão ineficaz de obras voltadas para a infraestrutura de transportes é capaz de determinar resultados ruins no desempenho da própria, bem como no uso desta para a sua destinação. Enquanto a metodologia está pautada na revisão bibliográfica, o método de abordagem ocupa-se na produção do debate acadêmico entre os diversos autores para, a 


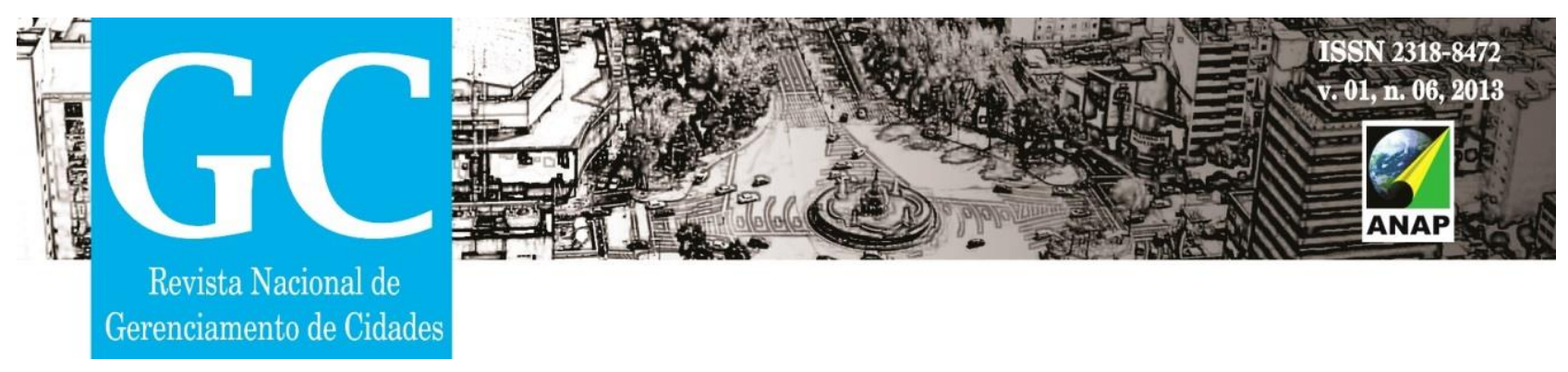

partir disto, criar uma forma de análise crítica sobre projetos voltados para ao objetivo citado.

Visto estes quesitos a cerca da formulação deste artigo, a divisão utilizada na composição das secções deste trabalho é percebida em 04 quatro partes. Esta Introdução ocupa-se da proposta a acerca da temática e o questionamento apresentados, os objetivos para alcançá-la. Em seguida, observam-se os principais conceitos das diversas áreas que aqui serão utilizados, bem como a Construção Civil aborda as obras voltadas para estruturas de Transportes e os respectivos impactos na produção e conexão dos espaços urbanos. Depois, ascende-se o debate sobre a questão da Sustentabilidade mediante a utilização racional dos recursos demandados em cada projeto, além de como este tipo de uso é capaz de maximizar resultados econômicos e o desempenho das obras, além de proporcionar menores impactos ao ambiente em transformação. Finamente, em Observações Finais, retoma-se a discussão teórica a acerca da Gestão em obras de Transportes a luz de tudo anteriormente exposto e os pertinentes apontamentos após a discussão elucidada ao longo deste escrito.

\section{ENGENHARIA CIVIL E INFRAESTRUTURA DE TRANSPORTES}

De acordo com Ferraz (2004) e Fleury (2007), a infraestruturas de transportes são definidas como equipamentos, instalações, objetos, vias e similares designados ao embarque, trânsito, transbordo e desembarque de passageiros e cargas ao longo do espaço. Dentro do estudo de Sistemas de Transportes, divide-se usualmente os estudos em Logística, Infraestrutura, Planejamento e Operações, novamente, tanto para passageiros como cargas. Enquanto o primeiro ocupa-se em grande parte de análises a respeito de cargas, os dois últimos são comuns às duas naturezas de transporte. Em geral, o planejamento está presente tanto nas etapas anteriores e posteriores a implantação de infraestruturas: enquanto no início definem-se os tipos de instalações, equipamentos e vias que são necessários para compor ou expandir determinados 


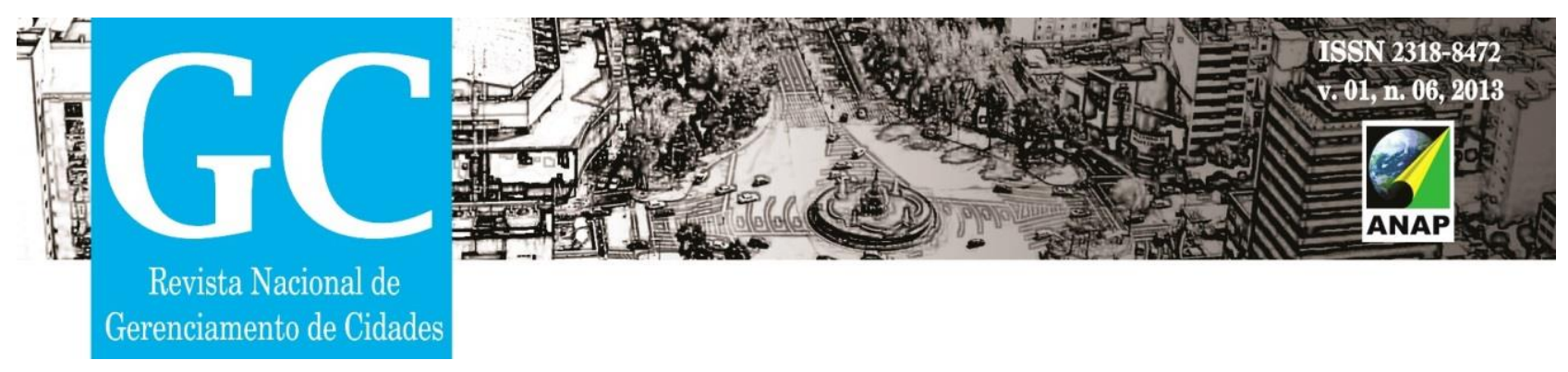

sistemas, a etapa posterior a construção destas encarrega-se do melhor uso presente para atender as demandas locais.

Com isto, Kawamoto (2010) menciona que tanto o planejamento da construção como do uso posterior da infraestrutura de transporte são etapas igualmente importantes dentro do projeto de composição de um sistema e, simultaneamente, estão interligadas: a construção determina o uso e, a demanda a cerca da estrutura é capaz de impulsionar a construção de novas instalações.

Complementarmente, Mankiw (2001) e Slack (2007) afirmam que os recursos disponíveis apresentam melhor uso quando sua implantação atende a grande parte das solicitações demandadas por uma determinada sociedade. Ou seja, a construção de uma nova rua pavimentada é justificada pelo uso intensivo de automóveis, sem que a maior parte do tempo permaneça congestionada. Desta maneira, os autores corroboram com o discurso de Chiavenato (2005) ao mencionar que o melhor uso de um recurso está na sua utiliza-se intensiva sem, contudo, alcançar constantemente o limite designado para o mesmo: assim, tanto como para o exemplo de uma rua, autoestradas e terminais possuem seu ponto ótimo de utilização quando são muito utilizados na maior parte do tempo com alguns períodos uso da capacidade máxima. No caso de subutilização ou superutilização destes recursos observam-se prejuízos econômicos diversos para a operação e manutenção dos equipamentos.

Ao planejar a construção de uma estrada, Pimenta (2004) menciona que três fatores são fundamentais para determinar a utilização de recursos e consequentemente, compor os custos desta: a escolha do traçado, materiais utilizados e o prazo para conclusão. O primeiro possui maior peso na tomada de decisão perante os fatores pois, conforme o mesmo autor, raras são as situações em que uma linha reta é a materialização de um determinado eixo de ligação e, desta maneira, a distância construída, topografia e morfologia do terreno aliados a classe (neste caso, vista como a quantidade de faixas e dispositivos presentes na obra construída) da via são determinantes para o uso de recursos em obras de terraplenagem, corte, aterro e nivelamento da estrutura. $O$ dimensionamento das cargas (típica e máxima) em circulação 


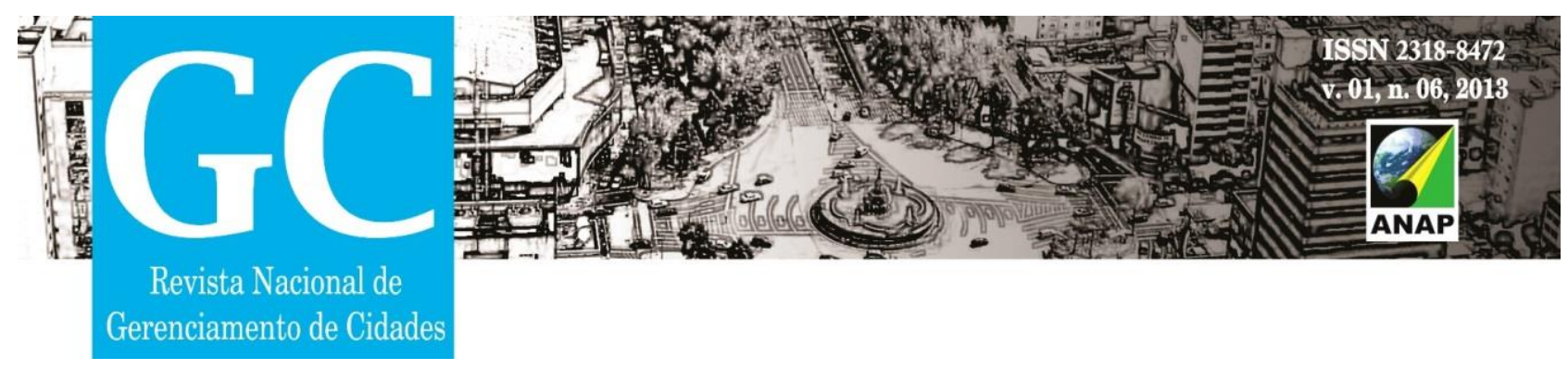

sobre a via também é um dos fatores que determina a utilização de recursos e custos do projeto: quanto maiores forem os pesos cargas e o número de veículos (destas) em circulação em conjunto com a classe escolhida, mais camadas alturas maiores e materiais com maior resistência são necessários para a construção em questão.

Assim, Vuchic (2007) une-se a esta discussão ao mencionar que, a construção de autoestradas não determina apenas a ligação entre duas ou mais localidades no espaço, mas também como as sociedades utilizam os recursos que possuem e os distribuem no território. Ele exemplifica esta afirmação ao mencionar que, nem sempre, a duplicação de uma via já saturada é recomendada para o aumento da fluidez no tráfego e, mais ainda, diversas alternativas, como por exemplo a construção de outra via paralela classe igual a saturada, pode apresentar melhor solução tratativa do problema em questão. Retomando Pimenta (2004), os materiais utilizados implicam em custos não apenas em sua compra, mas no transporte destes até o canteiro de obras e as técnicas utilizadas para são compactação. Isto, aliado ao prazo de entrega, determina o uso de mais profissionais e equipamentos para a conclusão e, certamente, adicionam maiores custos ao projeto. Desta maneira, a gestão eficiente pode salvar recursos minerais, financeiros e humanos.

Entretanto, não é possível desconsiderar que estas estruturas são construídas em um determinado espaço, habitado ou não e, após concluídas, provocam alteração em seu uso e ocupação. Desta maneira, a abordagem a partir do ponto de vista da Geografia é extremamente pertinente a este trabalho pois a análise de impactos de uma determinada obra de infraestrutura de transporte está sim inserida na vida urbana cotidiana do espaço onde será implementada e criará uma zona de influência de suas atividades. Assim, Corrêa (2006) menciona que a organização do espaço é determinada pelo uso dado as diferentes zonas e a acessibilidade a estas, simultaneamente. Assim, a construção de vias e edificações destinadas a receber passageiros e cargas é fundamental para o funcionamento e expansão das cidades.

Santos (2007) complementa esta informação ao mencionar que as cidades brasileiras são dependentes de seus sistemas locais, regionais e nacionais de transportes, os quais analisados como um sistema único, ajuda a compor a hierarquia 


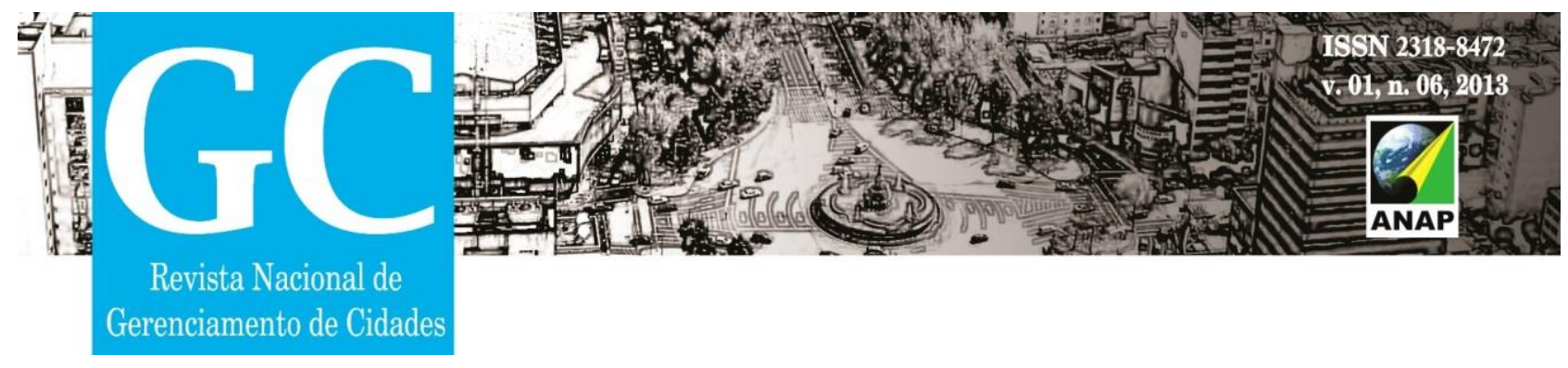

urbana dos municípios em território nacional. Certamente que o principal fator da área de influência das cidades é dada pela oferta de bens e serviços mais ou menos especializados sobre as outras, mas não é possível esquecer que o acesso aos mesmos é fundamental para ampliar o alcance desta área analisada. Desde a época colonial, as cidades portuárias confortam as principais centralidades do território pois, ali, realizavamse as trocas de bens e serviços, além do embarque e desembarque de passageiros, das áreas interioranas com o exterior. Atualmente, percebe-se que as maiores cidades brasileiras, mesmo situadas em locais distantes do litoral, possuem vias e estrutura que a conectam a outras unidades federadas e países estrangeiros.

\section{SUSTENTABILIDADE NA GESTÃO DE RECURSOS}

Segundo Araújo (2013), a gestão eficiente de construções é aquele que atende, ao mesmo tempo, a critérios de organização, economia de materiais, uso racional da mão de obra e distribuição (consequentemente o cumprimento) de tarefas ao longo do período de trabalho. Por mais que estes pontos elucidados também sejam os mesmos de autores como Mankiw (2001), Chiavenato (2005), Slack (2007) e Kawamoto (2010), o cumprimento na prática de todos ainda é uma tarefa de implementação extremamente trabalhosa.

Infelizmente, Araújo (2013) observa que as práticas atuais nos canteiros de obras fluem na direção contrária dos princípios de uma boa gestão na Construção Civil. Desta maneira, o que ocorre na prática é o uso cada vez mais intensivo de recursos de qualquer natureza e, ainda assim, as obras permanecem a erros grotescos de execução e atraso no prazo de entrega e conclusão tanto das etapas como do produto final.

Rossi (2003) cita que a sustentabilidade é um conceito amplo e não está associado somente a preservação de recursos naturais e dos espaços com predominância da natureza. Além disto, a sustentabilidade busca o equilíbrio não apenas entre as áreas urbanas e rurais com o meio natural, mas também o aproveitamento ideal dos recursos disponíveis no intuito de maximizar o benefício coletivo e gerar cada vez menos impactos 


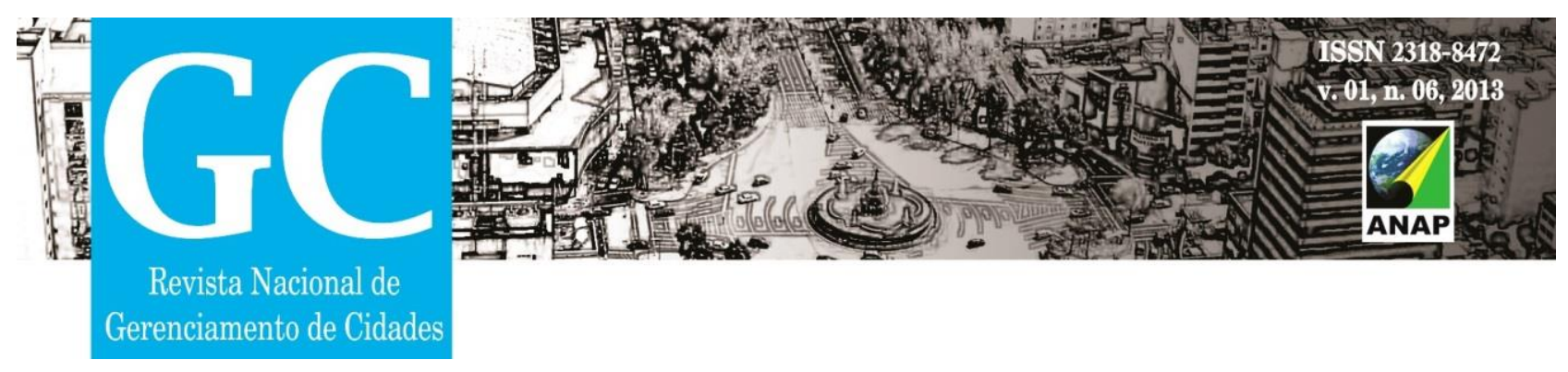

em intervenções e, por conseguinte, em construções. Ou seja, a preservação e requalificação de infraestruturas é um dos objetos de análise da corrente sustentável. Desta maneira, a construção de novas edificações e estruturas dentro das áreas urbanas, conforme também defendido por Gouvêa (2005) deve interferir o mínimo possível no cotidiano e circulação da população e, assim, já apresenta benefícios desde a etapa inicial. Ao continuar da mesma forma, observa-se a maximização do benefício pois o impacto antes e durante a implantação da infraestrutura em questão além de não gerar grandes transtornos, ao seu fim, também foi capaz de oferecer novas alternativas e conforto aos usuários.

Retomando Araújo (2013), os pontos levantados para a eficiência da gestão de obras de infraestrutura de transporte é crucial pois, não apenas representa a redução gradativa e escalar de recursos materiais tão necessários aos empreendimentos, mas também um ganho ímpar a qualidade de execução do serviço contratado. No tocante a construção de rodovias e ferrovias (superestrutura), Ferraz (2004) e Pimenta (2004) reforçam que a escolha do traçado e da classe da via são alguns dois fatores chave para o sucesso posterior do desempenho da estrutura, mesmo que na etapa construtiva esta demande obras mais caras e de execução mais complexas. Por exemplo, os autores citam como exemplo o uso de pontes um pouco mais longas para conectar morros ao longo do trecho ondulado de uma via: a execução de pontes encarece o custo inicial do projeto, mas após a entrega da obra, representa um benefício extra para os usuários pois não apenas reduz a distância percorrida, como impacta menos ao ambiente de influência e, em alguns casos, permite a manutenção de uma velocidade satisfatória para seguir o trajeto, todos as afirmações em contrapartida ao contorno de curvas de níveis. Da mesma maneira, a construção de túneis em nível ou subterrâneo são apontados como instrumentos de benefício ampliado ao conjunto de uma obra: se determinadas galerias de cinco quilômetros de extensão, por exemplo, reduzem o trecho montanhoso de vinte quilômetros em um determinado seguimento de estrada, não apenas é percebida a redução no tempo de percurso dos automóveis, mas também a economia de 


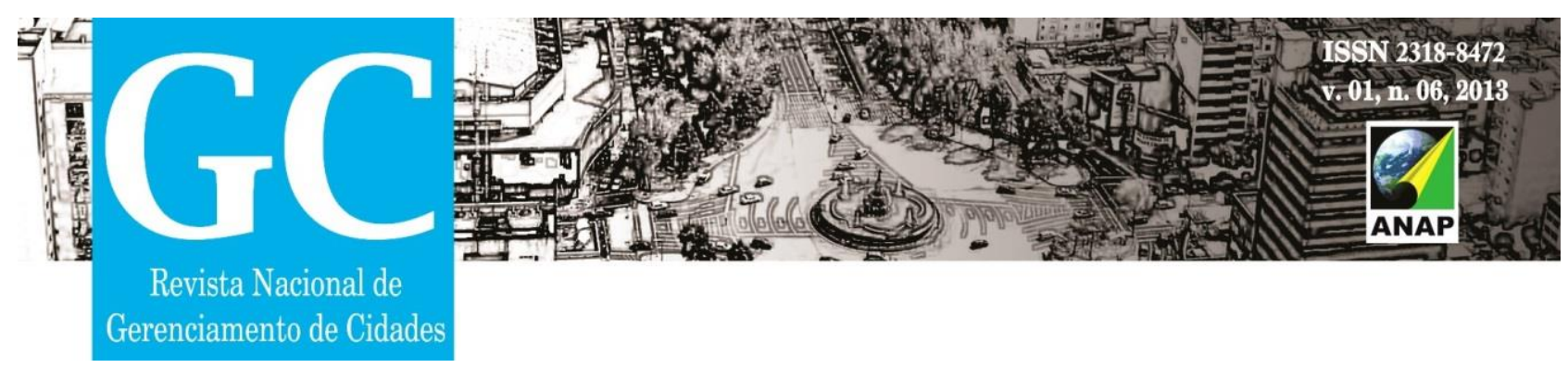

combustíveis, redução no desgaste das peças, bem como da poluição sonora e do ar no ambiente de entorno.

Entretanto, Mosso (2001) e Slack (2007) mencionam que a produção de uma determinada estrutura não pode estar focada apenas no benefício ao final de sua construção pois, em alguns casos, os custos para que a plenitude deste para a população seja alcançada é demasiado elevado e torna nulos os ganhos, além de eliminar a oportunidade de construção da estrutura. Desta maneira, não apenas o benefício final deve ser atingido, mas também o equilíbrio dos recursos financeiros é um dos pilares de sustentação do conceito de sustentabilidade.

De acordo com Chiavenato (2005), o gerenciamento de um empreendimento está pautado no aproveitamento dos recursos já disponíveis a manutenção de um constante ritmo em sua execução. Neste ponto, não mencionam-se apenas recursos materiais ou financeiros, como amplamente mencionado até o momento, mas também o melhor aproveitamento da mão de obra ao longo do tempo. A devida qualificação desta para o uso de equipamento e das melhores práticas de seus serviços também garante a harmonia a obra e auxilia na manutenção do ritmo. Focando além disto, se este ritmo, tão enfatizado, é mantido perceber-se-á no futuro que a contratação de mais trabalhadores para reforçar a construção não será necessária.

O planejamento é uma ferramenta essencial para aplicar e manter durante toda a vida útil de uma determinada estrutura. Como muitas das rotinas e itens podem ser mensurados nas etapas iniciais, o correto dimensionamento e execução de acordo com o que já está previsto reduz o risco de imprevistos ao longo do processo, tanto durante sua construção como de seu uso ao longo do tempo. Bannister (2010) exemplifica esta afirmação ao mencionar que o algumas linhas de metrô da cidade de Londres (Reino Unido) utilizam até os dias atuais alguns dos túneis abertos ao final do século XIX, graças ao dimensionamento previsto, adaptações a tecnologias ferroviárias mais recentes e, principalmente, a constante manutenção pela qual as galerias são submetidas. Desta maneira, ainda mencionando o autor, o ganho percebido é a continuação do serviço prestado com poucas interrupções e a alocação de recursos para a construção de 


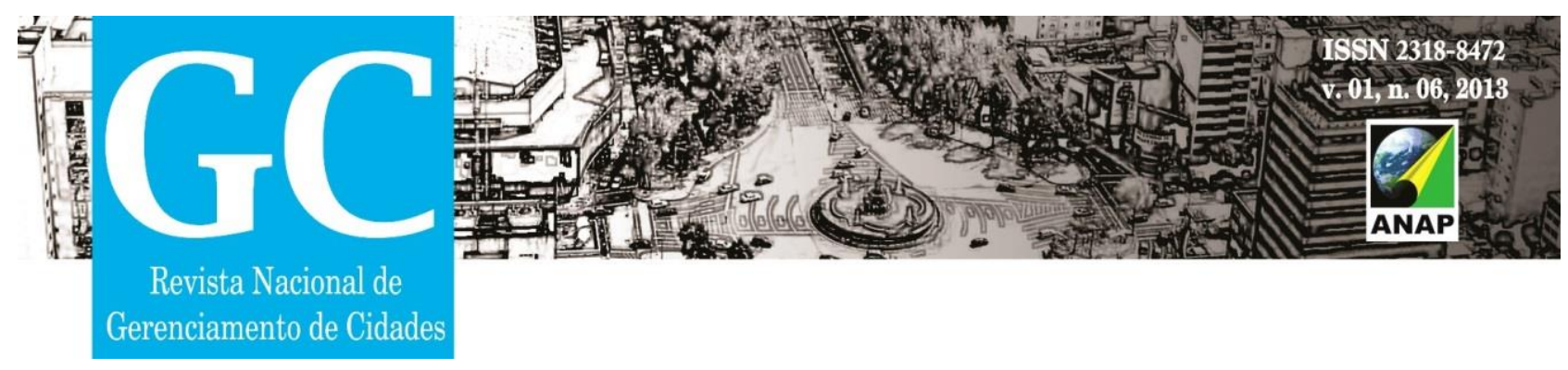

(possíveis) novos túneis, caso estes fossem desativados, podem ser empregados em outros equipamentos e estruturas, como a renovação do sistema de alimentação das composições e a modernização de estações, por exemplo.

Com isto, apenas com práticas de boa gestão, o metrô londrino neste aspecto por ser visto como sustentável. Evidentemente que outros sistemas metroviários presentes em outras cidades globais também possuem meios próprios de aproveitamento e conservação de seu material, tanto rodante como fixo, e exatamente estas técnicas permitem o melhor funcionamento e desempenho das estruturas existentes.

No cerne dos sistemas de transporte multimodos, além de todo planejamento e direcionamento de esforços para a circulação dos veículos está, segundo Ferraz (2004) Vuchic (2007) e Bannister (2010) o princípio de integração física das estruturas e distribuição balanceada dos fluxos no espaço de atuação de acordo com a capacidade de cada meio. Assim, é correto mencionar que cada meio possui um alcance determinado, dado pela sua capacidade de transporte de passageiros por viagens e, também, suas características intrínsecas. Utilizando um exemplo simples destas afirmações, para transportar um grande número de passageiros em espaços distantes (acima de 50 quilômetros, por exemplo), indica-se o uso de trens suburbanos de (pelo menos) 04 vagões, enquanto em distâncias medianas e com uma quantidade razoável de passageiros o uso de ônibus pneumáticos é mais recomendado.

Certamente que entre os trens intermetropolitanos de grandes capacidades e velocidades e os microônibus urbanos existem muitos veículos e modos de operação distintos. Por exemplo, a segregação semi-integral de uma via, com poucas intervenções e direitos de passagem (Rights of Way - ROW) tipo B, de acordo com Vuchic (2007), são alternativas de modo médio de transporte com capacidade razoável de passageiros caso o quantitativo seja insuficiente para a lotação média um trem suburbano. Desta maneira, a construção destes corredores de transporte rodoviários, conhecidos por Bus Rapid Transit - BRT, demandam serviços diferenciados daqueles de pavimentação tradicional de vias, tais como camadas com capacidade de suportar mais cargas dinâmicas e estáticas, pisos de rolamento diferenciado e, principalmente, esquemas especiais de cruzamentos e 


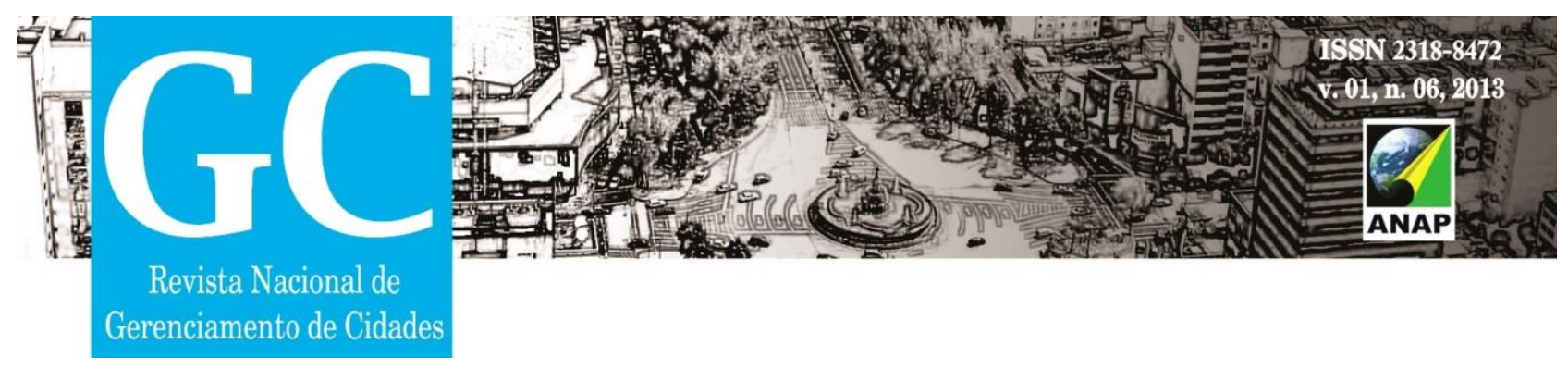

semaforização, onde a prioridade seja sempre dadas aos veículos que transportam mais passageiros. Acrescenta-se a isto, estações diferenciadas e com maior capacidade de embarque, transbordo e desembarque de passageiros.

Assim, estes corredores apresentam desafios de implementação e gestão tanto em sua construção como em posterior operação pois, em comparação ao sistema viário tradicional, apresenta tratamento e esquema de funcionamento diferenciado e demanda mais esforços e pessoal qualificado, bem como recursos distintos também.

\section{OBSERVAÇÕES FINAIS}

Santos (2009) observa conjuntamente a Corrêa (2006) que o funcionamento das economias capitalistas é dependente de seu sistema produtivo. Por conseguinte, este sistema possui como um de seus pilares de sustentação a rede de ligação entre localidades, independente do modo analisado. Desta maneira, a rede de transportes de um país, estado ou município é sim altamente dependente de seu sistema de circulação, tanto de cargas como de passageiros.

Diversos autores de campos distintos das Engeharias, Administração e Economia mencionam, sob enfoques pertinentes as suas formações, que o melhor aproveitamento dos recursos é obtido a partir da intensa utilização dos mesmos, bem como da ampliação dos benefícios perante os custos envolvidos. Também, ao utilizar as análises de Mankiw (2001), Chiavenato (2005) e Slack (2007) para o bom gerenciamento de recursos, observa-se que a programação e previsão destes realizada durante o planejamento anterior e posterior a execução das obras apresenta-se como um método eficiente para a obtenção das vantagens competitivas da estrutura bem como de seu desempenho ao longo do tempo.

Rossi (2003) complementa todas estas informações ao afirmar que a sustentabilidade não está restrita a uma determinada área ou campo de estudos, mas sim consolida-se como um conceito amplo e interdisciplinar que deve ser analisado sobre o escopo de diversas ciências. O objetivo buscado ao longo deste trabalho foi abordar o 


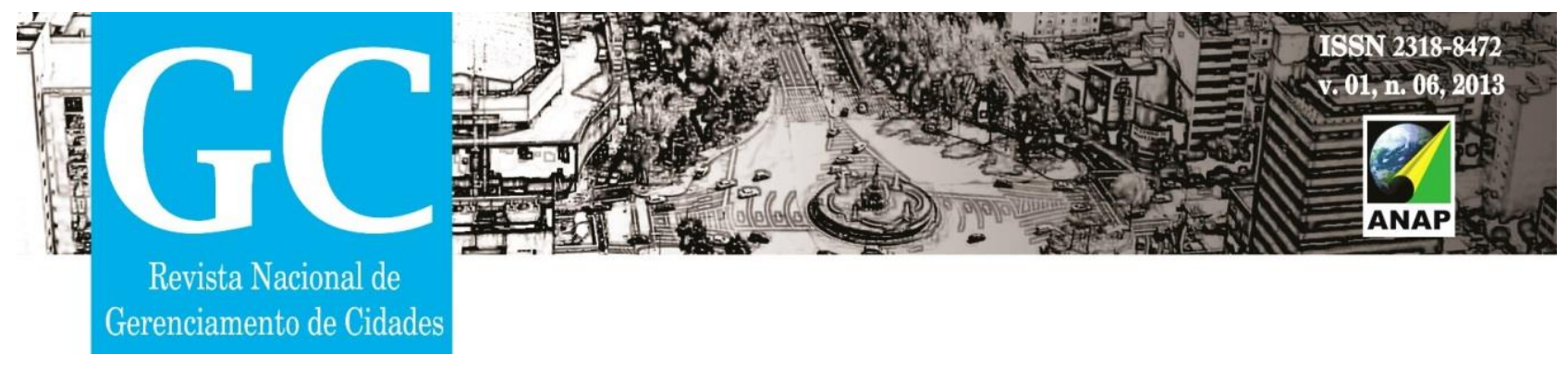

questionamento central a partir de alguns destes campos de conhecimento utilizando as infraestruturas voltadas aos transportes como materialização das afirmações presentes naquele conceito.

Finalmente, ao observarmos Araújo (2013) e suas proposições para novas práticas na gestão de obras na construção civil nacional, percebe-se as soluções apresentadas não são extremamente complexas e inovadoras, mas apenas a leitura da Engenharia Civil para métodos e processos de obras civis. Assim, sua implementação deveria ser uma rotina em todos os canteiros de obras referentes a infraestruturas de transporte.

\section{REFERÊNCIAS}

ARAÚJO, Luis Otávio. Notas de Aula do Curso de Gestão da Construção Civil. Rio de Janeiro: Mestrado Profissional em Engenharia Urbana da UFRJ, 2013.

BANISTER, David. Integrated Transport: From Policy to Practice. Londres e Nova (Reino Unido e Estados Unidos) York: Routledge, 2010.

BARAT, Josef. Logística, Transporte e Desenvolvimento Econômico. São Paulo: Editora CLA, 2007.

BRUEGMANN, Robert. Sprawl: A Compact History. Chicago (Estados Unidos): University of Chicago Press, 2005.

CHIAVENATO, Idalberto. Administração Financeira: Uma Abordagem Introdutória. Rio de Janeiro: Elsevier, 2005.

CORRÊA, Roberto Lobato. Estudos Sobre a Rede Urbana. Rio de Janeiro: Bertrand Brasil, 2006.

FERRAZ, Antônio Clóvis (Org). Transporte Público Urbano. São Carlos: Editora Rima, 2004.

FLEURY, Paulo Fernando (Org). Logística Empresarial. São Paulo: Editora Atlas, 2007. 


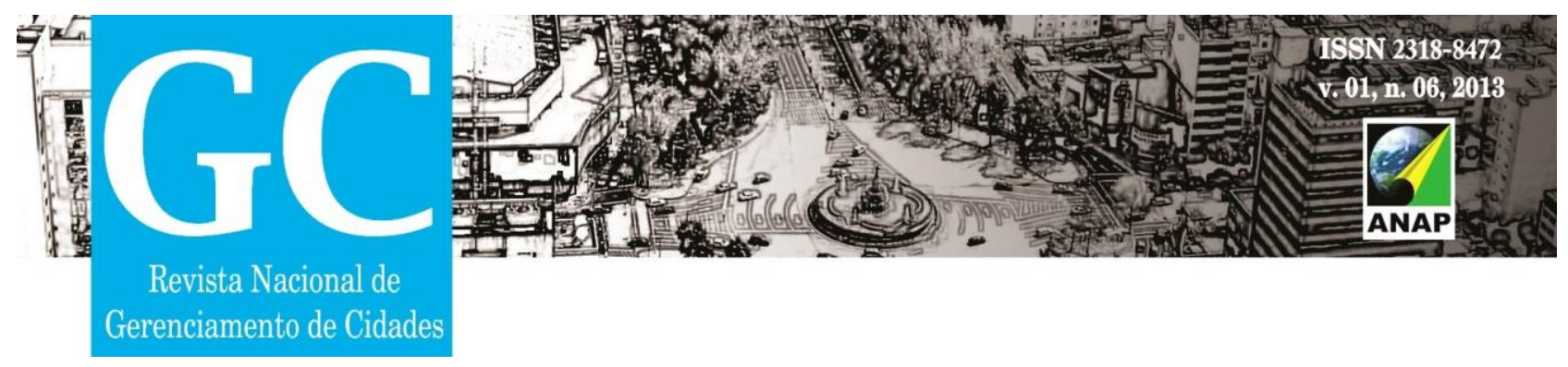

GOUVÊA, Ronaldo. A Questão Metropolitana no Brasil. Rio de Janeiro: FGV Editora, 2005.

KAWAMOTO, Eiji. Análise de Sistemas de Transportes. São Carlos: EdUSP, 2010.

MANKIW, Gregory. Introdução a Economia. Rio de Janeiro: Editora Campus, 2000.

MOSSO, Mário. Introdução à Estratégia em Qualidade. Rio de Janeiro: Editora ESC Cons, 2001.

PIMENTA, Carlos (Org). Projeto Geométrico de Rodovias. São Carlos: Editora Rima, 2004.

SANTOS, Milton. Economia Espacial. São Paulo: EdUSP, 2007.

SANTOS, Milton. A Urbanização Brasileira. São Paulo: EdUSP, 2009.

SLACK, Nigel (Org). Administração da Produção. São Paulo: Editora Atlas, 2007.

ROSSI, Angela Maria Gabriella. (Organizadora). Ambiente Construído: Reflexões sobre o Desenvolvimento Urbano Sustentável. Rio de Janeiro: Sete Letras, 2003.

VUCHIC, Vukan. Urban Public Transportation: Systems and Technology. Hoboken (Estados Unidos): Jon Wiley and Sons, 2007. 